\title{
Characterization of multiple first exons in murine prolactin receptor gene and the effect of prolactin on their expression in the choroid plexus
}

\author{
Hidemi Tabata1, Momoko Kobayashi ${ }^{1}$, Junko H Ikeda', Nobuhiro Nakao', Toru R Saito ${ }^{2}$ \\ and Minoru Tanaka ${ }^{1}$
}

\author{
${ }^{1}$ Department of Animal Science and ${ }^{2}$ Behavioral Neuroscience Section, Graduate School of Veterinary Medicine, Nippon Veterinary and Animal Science University, \\ Musashino, Tokyo 180-8602, Japan \\ (Correspondence should be addressed to M Tanaka; Email: mitanaka@nvlu.ac.jp)
}

\begin{abstract}
Prolactin (Prl) receptor (Prlr) gene is expressed in various brain regions, with the highest level present in the choroid plexus, a site for receptor-mediated PRL transport from the blood to cerebrospinal fluid. We investigated the regulatory mechanism of PrIr gene expression by PRL in the murine choroid plexus. We first examined the organization of the alternative first exons in murine Prlr gene. In addition to the three known first exons, $m E 1_{1}, m E 1_{2}$, and $m E 1_{3}$, two first exons, $\mathrm{mE} 1_{4}$ and $\mathrm{mE} 1_{5}$, were newly identified by cDNA cloning. Each first exon variant of Prlr mRNA exhibited tissuespecific or generic expression. In the choroid plexus of mice, the expression levels of $m E 1_{3^{-}}, m E 1_{4^{-}}$, and $m E 1_{5}-P r l r$ mRNAs were increased in the lactating mice compared with those in the diestrus mice. Furthermore, the expression level of $\mathrm{mE1}_{4}$-PrlrmRNA was decreased in the PRL-deficient $\left(\mathrm{Prl}^{-/-}\right)$mice compared with the PRL-normal $\left(\mathrm{Prl}^{+/+}\right.$and $\mathrm{Prl}^{+/-}$) mice. In the ovariectomized $\mathrm{Prl}^{-/-}$mice, the expression level of $\mathrm{mE1}_{4}{ }_{-} \mathrm{PrlrmRNA}$ was significantly increased by PRL administration but not by $17 \beta$-estradiol administration. The expression levels of the two last exon variants of Prlr mRNAs, encoding the long and short cytoplasmic regions of PRLR, were also increased in the lactating mice and decreased in the $\mathrm{Prl}^{-1-}$ mice. These findings suggest that PRL stimulates the PrIr gene expression through the transcriptional activation of $\mathrm{mE}_{1}$ first exon, leading to increases in the long- and short-form variants of Prlr mRNA in the murine choroid plexus.
\end{abstract}

Journal of Molecular Endocrinology (2012) 48, 169-176

\section{Introduction}

Prolactin (PRL) exhibits many physiological functions, including a number of brain functions such as maternal behavior, stress tolerance, food intake, and sexual behavior (Bole-Feysot et al. 1998, Freeman et al. 2000). All these functions of PRL are mediated by PRL receptor (PRLR). PRLR mRNA expression has been detected in various brain regions in mammals, with the highest level detected in the choroid plexus (Brooks et al. 1992, Chiu et al. 1992, Di Carlo et al. 1992, Ouhtit et al. 1993, Chiu \& Wise 1994, Nagano \& Kelly 1994, Fujikawa et al. 1995, Brown et al. 2010). It is believed that PRL is transported from the blood to the cerebrospinal fluid (CSF) by a PRLR-mediated system in this brain region (Walsh et al. 1987). In addition, it has been reported that PRL enhances its own uptake in the choroid plexus (Mangurian et al. 1992). Supporting this function, a high level of PRLR expression in the choroid plexus has been observed during lactation when the plasma PRL level is also high (Muccioli \& Di Carlo 1994, Escalada et al. 1996, Sugiyama et al. 1996, Pi \& Grattan 1999, Augustine et al. 2003, Pi et al. 2003, Nogami et al. 2007, Anderson et al. 2008). Also, PRLR expression in this brain region increases during the stress response, accompanying an increase in the plasma PRL level (Fujikawa et al. 1995). Furthermore, both peripheral and central administration of PRL have been shown to increase the PRLR expression in the choroid plexus (Muccioli \& Di Carlo 1994, Fujikawa et al. 2004). These findings suggest that PRL upregulates $P R L R$ gene expression in the choroid plexus.

In mammals such as rats, mice, and humans, PRLR gene expression is regulated by the transcriptional activation of multiple alternative first exons encoding $5^{\prime}$-untranslated regions. In rat Prlr gene, five alternative first exons, $\mathrm{E} 1_{1}, \mathrm{E} 1_{2}, \mathrm{E} 1_{3}, \mathrm{E} 1_{4}$, and $\mathrm{E} 1_{5}$, have been identified previously ( $\mathrm{Hu}$ et al. 1996, Moldrup et al. 1996, Tanaka et al. 2002, 2005). In rats, the $\mathrm{E} 1_{1}$ variant of Prlr mRNA is specifically expressed in the gonadal tissues $\left(\mathrm{Hu}\right.$ et al. 1997) and the $\mathrm{E} 1_{2}$ variant is transcribed in the liver and kidney (Moldrup et al. 1996, Tanaka et al. 2005). In addition, the $\mathrm{E} 1_{3}$ variant is expressed in a wide range of tissues ( $\mathrm{Hu}$ et al. 1998), whereas the $\mathrm{E} 1_{4}$ variant is preferentially expressed in the brain (Tanaka et al. 2002). Finally, the $\mathrm{E} 1_{5}$ variant is used in the brain, liver, and kidney (Tanaka et al. 2005). In murine Prlrgene, three first exons homologous to rat 
$\mathrm{E} 1_{1}, \mathrm{E} 1_{2}$, and $\mathrm{E} 1_{3}$ (referred to as $\mathrm{mE} 1_{1}, \mathrm{mE}_{2}$, and $\mathrm{mE} 1_{3}$ respectively) have been detected to date (Davis \& Linzer 1989, Hu et al. 1997, 1998). In human PRLR gene, six alternative first exons, $\mathrm{hE} 1_{3}, \mathrm{hE} 1 \mathrm{~N} 1, \mathrm{hE} 1 \mathrm{~N} 2$, hE1N3, hE1N4, and hE1N5, have been identified (Hu et al. 1999, 2002).

In addition to the alternative first exons, mammalian $P R L R$ genes also contain alternative last exons encoding the C-terminal regions of the long or short forms of PRLR proteins. In rats and humans, the two last exon variants of PRLR mRNA, one for the long form of protein and another for the short form, are present (Boutin et al. 1989, Shirota et al. 1990, Nagano \& Kelly 1994, Trott et al. 2003). In murine Prlr mRNA, the four last exon variants, one long form (Prlr $L)$ and three short forms (Prlr-S1, -S2, and -S3), have been identified by cDNA cloning (Davis \& Linzer 1989, Clarke \& Linzer 1993, Moore \& Oka 1993). However, the nucleotide sequence of PRLR-S3 contains one nucleotide deletion in codon 78, which results in the appearance of a stop codon after the following 19 amino acid residues. Therefore, PRLR-S3 encodes a truncated form of PRLR protein and is considered to be a transcript of a pseudogene (Davis \& Linzer 1989). In rats and mice, the long-form PRLR is the predominant form in most tissues except for the liver where the short form is abundant (Davis \& Linzer 1989, Shirota et al. 1990). Intracellular signaling of the long form is mainly mediated by the JAK2/STAT5 pathway (Bole-Feysot et al. 1998, Freeman et al. 2000). Although, short-form PRLR can activate the MAP kinase pathway (Das \& Vonderhaar 1995), its intracellular signaling system is poorly understood.

To gain a better understanding of the molecular mechanisms of PRL function in the choroid plexus, it is essential to clarify the regulatory mechanisms involved in Prlr gene expression in the choroid plexus. In this study, we first demonstrated the presence of the five distinct first exons, including two newly identified first exons in murine Prlr gene, and then examined the tissue expression patterns of the individual first exon variants of Prlr mRNA. Subsequently, we used hyperprolactinemic (lactating) and PRL-deficient mice to examine the effects of PRL on the expression of the first exon variants together with the expression of the last exon variants of Prlr mRNA encoding long- or short-form PRLR in the choroid plexus.

\section{Materials and methods}

\section{Animals and hormone treatments}

C57BL/6j mice were purchased from Oriental Yeast (Tokyo, Japan). PRL-deficient $\left(\mathrm{Prl}^{-/-}\right)$mice were generated as described previously (Horseman et al.
1997). The mice were housed under controlled temperature $\left(22^{\circ} \mathrm{C}\right)$ and lighting conditions $(12 \mathrm{~h}$ light:12 h darkness, lights were turned on at $0700 \mathrm{~h}$ ). Food and water were given to the mice ad libitum. The presence of estrus cycle in the mice was determined by performing vaginal smears. Ovariectomy was performed on the mice at 5 weeks of age under pentobarbital anesthesia, and the hormone treatment was started on the mice after 2 weeks of their recovery. $17 \beta$-estradiol ( $\mathrm{E}_{2}$; Nacalai Tesque, Kyoto, Japan) and human PRL (Shikibo Lifetech, Inc., Osaka, Japan) were individually dissolved in sesame oil and PBS respectively. $\mathrm{E}_{2}(1.25 \mathrm{mg} / \mathrm{kg}$ body weight) was injected s.c. into the back of the necks of the mice daily for 7 days, and PRL ( $2.5 \mathrm{mg} / \mathrm{kg}$ body weight) was s.c. injected twice daily (at 0900 and $1800 \mathrm{~h}$ ) for 3 days. The effective doses and frequencies of $\mathrm{E}_{2}$ and PRL were determined by preliminary experiments. The animals were killed by decapitation $24 \mathrm{~h}$ after the last injection. All procedures were performed in accordance with the National Institutes for Health's guidelines regarding the principles of animal care.

\section{RNA isolation}

After the mice were killed, their tissues were rapidly removed and frozen in liquid nitrogen. The choroid plexus of each mouse was carefully removed from the forebrain. Total RNA was extracted from the tissues with TRIzol (Invitrogen). Poly(A) ${ }^{+}$RNA was prepared from the total RNA of the forebrain with OligoTex Super-dT30 (Takara, Shiga, Japan) according to the manufacturer's instructions.

\section{cDNA cloning of the first and last exon variants of PrIr mRNA}

The $5^{\prime}$-end of the Prlr cDNA was synthesized from the poly(A) ${ }^{+}$RNA prepared from the forebrain by the oligo-capping method (Maruyama \& Sugano 1994) using Cap Site cDNA dT kit (Nippon Gene, Toyama, Japan). Briefly, the cap structure of poly(A) ${ }^{+}$RNA was removed with tobacco acid pyrophosphatase, and the decapped mRNA was recapped with an oligonucleotide RNA linker. Subsequently, the oligo-capped mRNA was reverse transcribed with oligo-dT primer, and the resultant CDNA was subjected to the first PCR using a combination of 1RDT linker primer supplied in the kit and murine PRLR-specific antisense primer. Then, the PCR products were subjected to nested PCR using a combination of 2RDT linker primer supplied in the kit and another murine PRLR-specific antisense primer. Prle-S4 cDNA was amplified from the cDNA with a sense primer and an antisense primer derived from the reported Prls-S3 cDNA sequence. The sequences of 
Table 1 PCR primers

\begin{tabular}{|c|c|c|c|c|c|}
\hline Application & cDNA & Forward $\left(5^{\prime}-3^{\prime}\right)$ & Accession no. & Reverse $\left(5^{\prime}-3^{\prime}\right)$ & Accession no. \\
\hline \multirow[t]{3}{*}{ cDNA cloning } & $5^{\prime}$-variants & gatgctagctgcgagtcaagtc & $1 \mathrm{RDT}^{\mathrm{a}}$ & ggtaggtggcaaccattttacc & L13593 \\
\hline & $5^{\prime}$-variants & cgagtcaagtcgacgaagtgc & $2 \mathrm{RDT}^{\mathrm{a}}$ & ccgaggaggctctggttcaac & L13593 \\
\hline & $m P R L R-S 4$ & tagggaaacgtagaagagca & M22957 & tcagaaaacccacactgcag & M22957 \\
\hline \multirow[t]{10}{*}{ Real-time PCR } & $m E 1_{2}-P R L R$ & actgtctgctcttttcagaagtct & M22959 & ggacaagcagcatgtaagca & L13593 \\
\hline & $m E 1_{3}-P R L R$ & attttacacggggctcagg & BC005555 & caggggaacgacatttgtg & L13593 \\
\hline & $m E 1_{4}-P R L R$ & agagaggcaccctccacag & $-\mathrm{b}$ & caggggaacgacatttgtg & L13593 \\
\hline & $m E 1_{5} P R L R$ & caggctgtgactccatgtgt & $-^{c}$ & caggggaacgacatttgtg & L13593 \\
\hline & Total PRLR & tgccatctgcacttgcttac & L13593 & caggggaacgacatttgtg & L13593 \\
\hline & $m P R L R-L$ & atcattcaccggecgttctctc & L13593 & ccagcaagtcctcacagtca & L13593 \\
\hline & $m P R L R-S 1$ & gcagtggctttgaagggtta & L13593 & ccagggaagtcaactggaga & M22958 \\
\hline & $m P R L R-S 2$ & atcattcaccggccgttctctc & L13593 & ggctgtggtcgagtgggtaa & M22959 \\
\hline & $m P R L R-S 4$ & atcattcaccggecgttctctc & L13593 & gtatttgcttggagagccagt & AB643813 \\
\hline & $m G A P D H$ & tgtcagcaatgcatcctgca & NM_008084 & ccgttcagctctgggatgac & NM_008084 \\
\hline
\end{tabular}

aPrimers supplied with the Cap Site cDNA kit.

${ }^{b}$ Sequences in the Fig. $1 \mathrm{~A}$.

${ }^{\mathrm{c}}$ Sequences in the Fig. 1B.

primers used are shown in Table 1 . The amplified DNA was cloned into the pGEM-T Easy vector (Promega) and sequenced with the BigDye Terminator v3.1 Cycle Sequencing kit (Applied Biosystems, Foster City, CA, USA) and the ABI PRISM 310 Genetic Analyzer (Applied Biosystems).

\section{Real-time PCR analysis}

Total RNA $(5 \mu \mathrm{g})$ was reverse transcribed at $50{ }^{\circ} \mathrm{C}$ for $60 \mathrm{~min}$ in $20 \mu \mathrm{l}$ reaction mixture containing 200 units of Superscript III transcriptase (Invitrogen), $0.5 \mathrm{mM}$ dNTPs, $10 \mathrm{mM}$ dithiothreitol, $50 \mu \mathrm{M}$ random primers, and $1 \times$ first-strand buffer supplied by the manufacturer. After the inactivation of the reverse transcriptase by heating at $70{ }^{\circ} \mathrm{C}$ for $15 \mathrm{~min}$, the cDNA product was subjected to real-time PCR with the Real-time PCR system 7500 (Applied Biosystems, Tokyo, Japan). PCR was carried out with a thermal protocol consisting of $95^{\circ} \mathrm{C}$ for $15 \mathrm{~s}$ and $60^{\circ} \mathrm{C}$ for $35 \mathrm{~s}$ in $25 \mu$ buffer containing $1 \times$ Platinum SYBR Green qPCR SuperMix-UDG (Invitrogen) and $0 \cdot 2 \mu \mathrm{M}$ each of the forward and reverse primers listed in Table 1. Quantitative measurement was performed by establishing a linear amplification of serial dilutions of the plasmid DNA (pGEM-T Easy vector) containing each cDNA fragment amplified by the PCR with the first- or last exon-specific primers.

\section{Statistical analysis}

All data were analyzed by one-way ANOVA and are expressed as mean \pm s.D. The significance of the $F$ values obtained was confirmed by Tukey's post-hoc test. All analyses were performed using GraphPad Prism Software version 4 (GraphPad Software, San Diego, CA, USA).

\section{Results}

\section{Identification and genomic organization of multiple first exons in murine PrIr gene}

Both the $\mathrm{mE}_{4^{-}}$and the $m E 1_{5}$-Prlr cDNAs were cloned from the brain by the oligo-capping method. The sequences of $\mathrm{mE} 1_{4}$ - and $\mathrm{mE} 1_{5}$-first exons are shown in Fig. $1 \mathrm{~A} . \mathrm{mE}_{4}$ and $\mathrm{mE}_{5}$ shared $69 \cdot 4$ and $91 \cdot 8 \%$ sequence identities with rat $\mathrm{E} 1_{4}$ and $\mathrm{E} 1_{5}$ respectively. A computer-assisted sequence search revealed the positions of the five first exons in Prlr gene (NT 039618) located in chromosome 15 of the

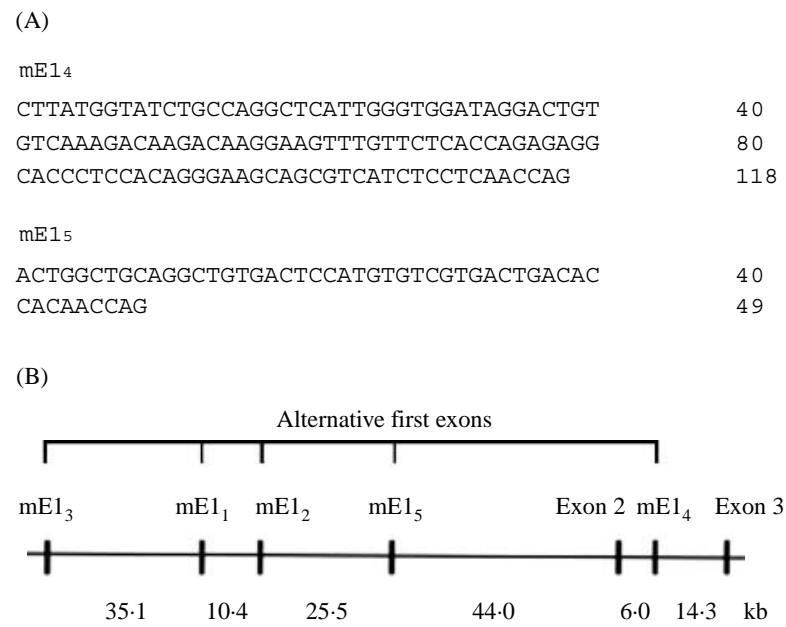

Figure 1 Nucleotide sequences of $\mathrm{mE} 1_{4}$ and $\mathrm{mE} 1_{5}$ first exons and schematic representation of the organization of the five first exons of murine Prlrgene. (A) The sequences of the first exon portions of $m E 1_{4}$ - and $m E 1_{5}$ Prlr cDNAs are shown. The sequence spanning exon 1 to exon 3 of murine Prlrgene was obtained from the Mouse Genome Database (NT 039618.3). (B) The diagrams show arrangement of the five first exons. The exons in gene are represented by vertical bars. 

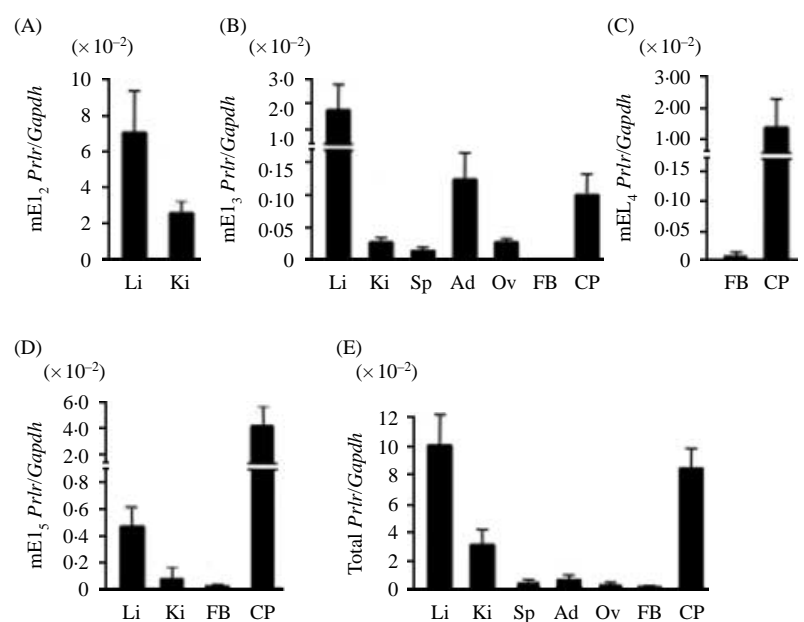

Figure 2 Tissue distributions of the first exon variants of murine PrlrmRNA. Expression levels of (A) $\mathrm{mE}_{2_{2}},(\mathrm{~B}) \mathrm{mE} 1_{3^{-}},(\mathrm{C}) \mathrm{mE} 1_{4^{-}}$, (D) $\mathrm{mE1}_{5^{-}}$, and (E) total Prlr mRNAs in the liver (Li), kidney (Ki), spleen (Sp), adrenal gland (Ad), ovary (Ov), forebrain (FB), and choroid plexus $(\mathrm{CP})$ in diestrus mice were determined by real-time PCR. Values are expressed as relative to the value of Gapdh mRNA, and they represent mean \pm s.D. $(n=4)$. Data for each mRNA variant are shown in the tissues where each mRNA was detected.

C57BL/6 mouse strain. Figure 1B shows a schematic representation of the organization of these first exons together with exons 2 and 3 in Prlrgene. $\mathrm{mE}_{4}$ was located downstream of exon 2, accounting for the lack of the exon 2 sequence in the $\mathrm{mE} 1_{4}$-cDNA (data not shown).

\section{Expression levels of the first exon variants of Prlr mRNAs in murine tissues}

The expression levels of Prlr mRNAs containing each of the first exons in the tissues of the diestrus mice were examined by real-time PCR (Fig. 2). The expression of $m E 1_{r}$ Prlr mRNA was not observed in any tissues under the experimental conditions we used. However, $m E 1_{2}$ Prlr mRNA was expressed in both the liver and the kidney, with higher levels present in the liver. The $m E 1_{3}$ Prlr mRNA expression was observed in all the tissues examined, with markedly high levels in the liver and choroid plexus and moderately high levels in the adrenal gland. The $m E 1_{4} P r l r$ mRNA was expressed in the choroid plexus and forebrain, with remarkably high levels present in the choroid plexus. Finally, $\mathrm{mE}_{5}{ }_{5} \mathrm{Prlr}$ mRNA expression was observed in the choroid plexus, forebrain, liver, and kidney, with the most abundant levels apparent in the choroid plexus. The expression levels of total Prlr mRNA were markedly high in the liver and choroid plexus, moderately high in the kidney, and relatively low in the other tissues; this reflects the expression levels of each of the first exon in the respective tissues.
Expression levels of the first exon variants of Prlr mRNAs in the choroid plexus of diestrus, lactating, and PRL-deficient mice

As the expression of $m E 1_{I^{-}}$and $m E 1_{2}-\operatorname{Prlr}$ mRNAs were not observed in the choroid plexus at day 3 of lactation mice as well as the diestrus mice by RT-PCR analysis (data not shown), the expression levels of $m E 1_{3}, m E 1_{4}$, and $m E 1_{5}-P r l r$ mRNAs in the choroid plexus were examined in the diestrus, lactating, and $\mathrm{Prl}^{-/-}$mice (Fig. 3). In the wild-type $\left(\mathrm{Prl}^{+/+}\right)$mice, the levels of $m E 1_{3}, m E 1_{4}$, and $m E 1_{5}-P r l r$ mRNAs were significantly increased at day 3 of lactation compared with those at the diestrus state, with the most prominent difference occurring in $m E 1_{4} P r l r$ mRNA. Reflecting these results, the level of total Prlr mRNA was markedly increased at the lactation state. The $m E 1_{4} P r l r$ mRNA level was significantly lower in the diestrus $\mathrm{Prl}^{-/-}$mice than in the diestrus $\mathrm{Prl}^{+/-}$mice, whereas no significant difference was observed in the levels of $m E 1_{3}$ and $m E 1_{5}$-Prlr mRNAs. In addition, the total Prlr mRNA level was significantly lower in the diestrus $\mathrm{Prl}^{-/-}$mice than in the diestrus $\mathrm{Prl}^{+/-}$mice.
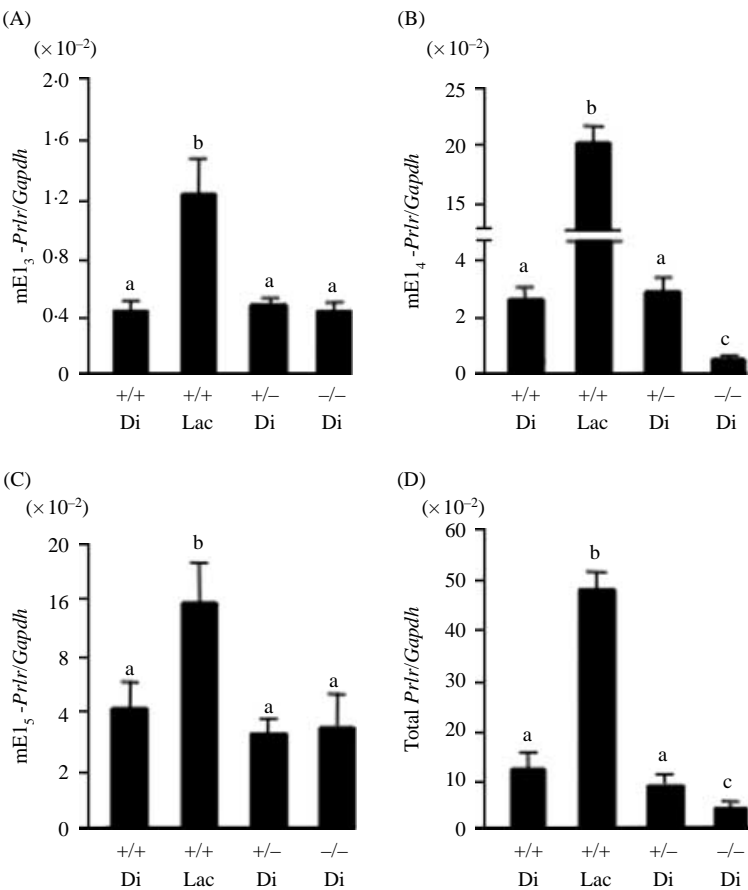

Figure 3 Expression levels of the first exon variants of PrlrmRNA in the choroid plexus of diestrus, lactating, and PRL-deficient mice. The expression levels of $(A) \mathrm{mE}_{3^{-}},(B) \mathrm{mE1}_{4^{-}},(\mathrm{C}) \mathrm{mE} 1_{5^{-}}$, and (D) total PrIrmRNAs in diestrus (Di) and day 3 lactating (Lac) $\mathrm{Prl}^{+/+}$mice, and diestrus $\mathrm{Prl}^{+/-}$and $\mathrm{Prl}^{-/-}$mice were determined by real-time PCR. Values are expressed as relative to the value of Gapdh mRNA, and they represent mean \pm S.D. $(n=4)$. Values with different letters are significantly different $(P<0.05)$. 
Effects of PRL and $E_{2}$ on expression levels of the first exon variants of PrIr mRNA in the choroid plexus

The effects of PRL and $\mathrm{E}_{2}$ on the expression levels of $m E 1_{5}, m E 1_{4}$, and $m E 1_{5}-$ PrlrmRNAs in the choroid plexus were examined in the sham-operated or ovariectomized $\mathrm{Prl}^{+/-}$and $\mathrm{Prl}^{-/-}$mice (Fig. 4). Neither the ovariectomy nor the administration of PRL or $\mathrm{E}_{2}$ had a significant effect on the expression levels of $\mathrm{mE1}_{3}$ or $\mathrm{mE1}_{5} \mathrm{Prlr}$
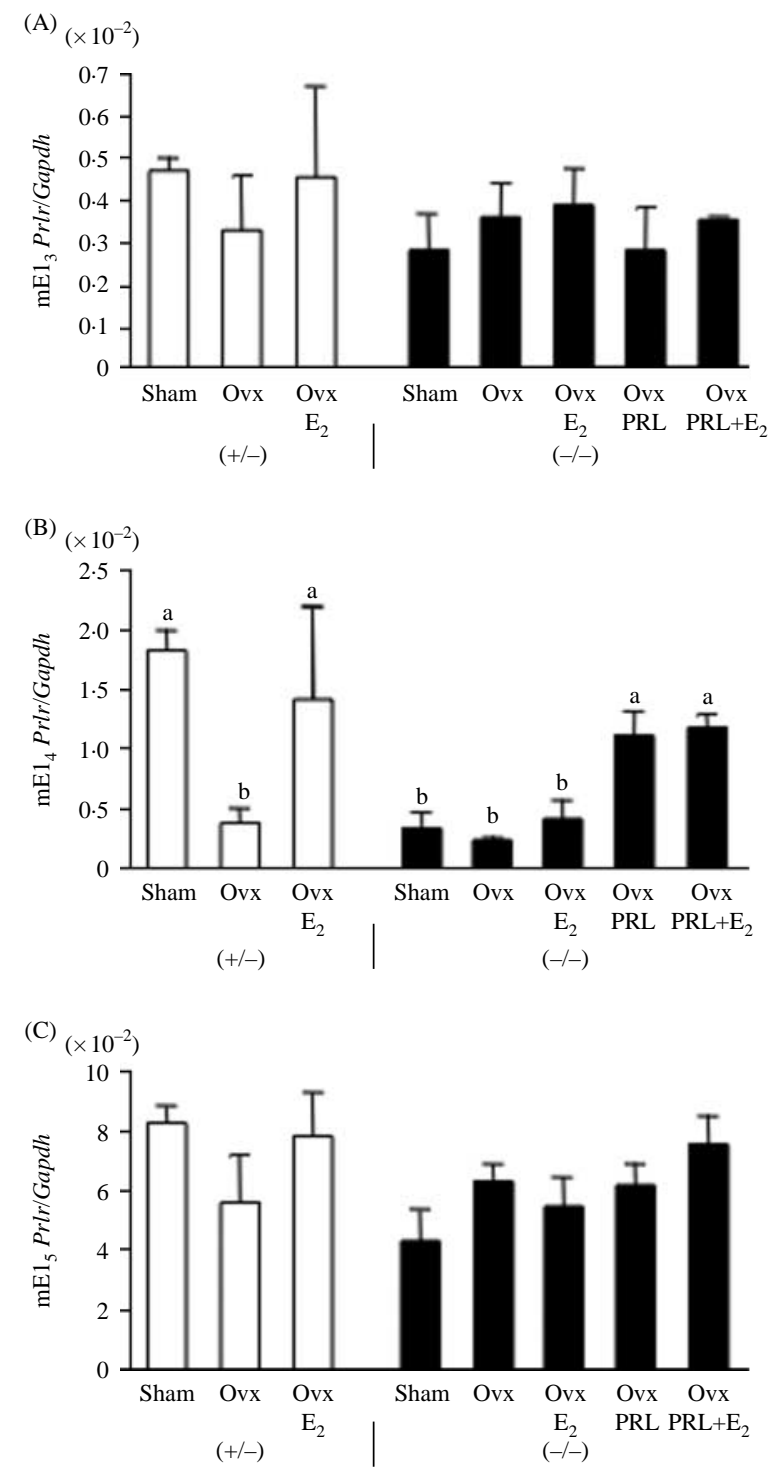

Figure 4 Effects of PRL and estrogen treatment on the expression levels of the first exon variants of PrIrmRNAs in the choroid plexus of $\mathrm{Prl}^{+/-}$and $\mathrm{Prl}^{-1-}$ mice. Expression levels of (A) $\mathrm{mE1}_{3}{ }^{-}$,

(B) $m E 1_{4^{-}}$, and (C) $m E 1_{5}$-Prlr mRNAs in the choroid plexus of sham-operated (Sham) mice, ovariectomized (Ovx) mice, estrogen-treated ovariectomized $\left(\mathrm{Ovx}+\mathrm{E}_{2}\right)$ mice, PRL-treated ovariectomized ( $\mathrm{Vvx}+\mathrm{PRL}$ ) mice, and estrogen- and PRL-treated ovariectomized ( $\left.\mathrm{Ovx}+\mathrm{E}_{2}+\mathrm{PRL}\right)$ mice are presented. Values represent mean \pm S.D. $(n=4)$. Values with different letters are significantly different $(P<0.05)$.
mRNAs in the $\mathrm{Prl}^{+/-}$or $\mathrm{Prl}^{-/-}$mice. However, in the $\mathrm{Prl}^{+/-}$mice, the expression level of $m E 1_{4} \mathrm{Prlr}$ mRNA was markedly decreased by the ovariectomy and was recovered by the $\mathrm{E}_{2}$ administration. In the $\mathrm{Prl}^{-/-}$mice, neither the ovariectomy nor the $\mathrm{E}_{2}$ administration had an effect on the expression level of $m E 1_{4} P r l r$ mRNA, although the PRL administration significantly increased the expression level. No additive effect was observed by the simultaneous administration of PRL and $\mathrm{E}_{2}$.

\section{Identification of the murine ortholog for rat short-form PrIr mRNA and genomic organization of the multiple last exons in murine PrIr gene}

A cDNA that encodes the mouse ortholog for the rat short-form PRLR was cloned from the choroid plexus of a C57BL/ 6 mouse (Fig. 5A). The obtained cDNA, which is referred to as Prlr-S4, encoded a protein consisting of 310 amino acids (accession no. AB643813), showing 93\% overall sequence identity with the rat short-form PRLR. The nucleotide sequence of Prlr-S4 was similar to that of Prlr-S3 cDNA cloned from a Swiss Webster mouse (Davis \& Linzer 1989), but there are considerable mismatches including the deletion of a single nucleotide at codon 78 , which is the cause for the truncated amino acid sequence of PRLR-S3. Four alternative last exons encoding the $3^{\prime}$-end sequences of Prlr-L, $-S 1,-S 2$, or $-S 4$ mRNAs were found in Prlrgene of the C57BL/6 mouse (NT 039618). The arrangement of the alternative last exons is shown in Fig. 5B.

\section{Expression levels of the last exon variants of Prlr mRNAs in the choroid plexus of diestrus, lactating, and PRL-deficient mice}

The expression levels of the last exon variants of Prlr mRNAs in the choroid plexus were examined by real-time PCR (Fig. 6). These results revealed that Prlr $L$ mRNA was abundantly expressed, but among the three short-form variants, only Prls-S4 mRNA was detected at a measurable level. In the $\mathrm{Prl}^{+/+}$mice, the expression level of PRLR $L$ mRNA was markedly higher in the lactation state than in the diestrus state. The expression levels of Prlr-S4 mRNA in the lactating mice were also significantly higher than those in the diestrus mice. The expression levels of Prlv- $L$ and Prlv-S4 mRNAs in the diestrus $\mathrm{Prl}^{+/-}$mice were similar to those in the diestrus $\mathrm{Prl}^{+/+}$mice and significantly decreased in the diestrus $\mathrm{Prl}^{-/-}$mice.

\section{Discussion}

In addition to the three known first exons, two other distinct first exons were identified in murine Prlr gene. These five first exons are similar to the rat counterparts 
(A)

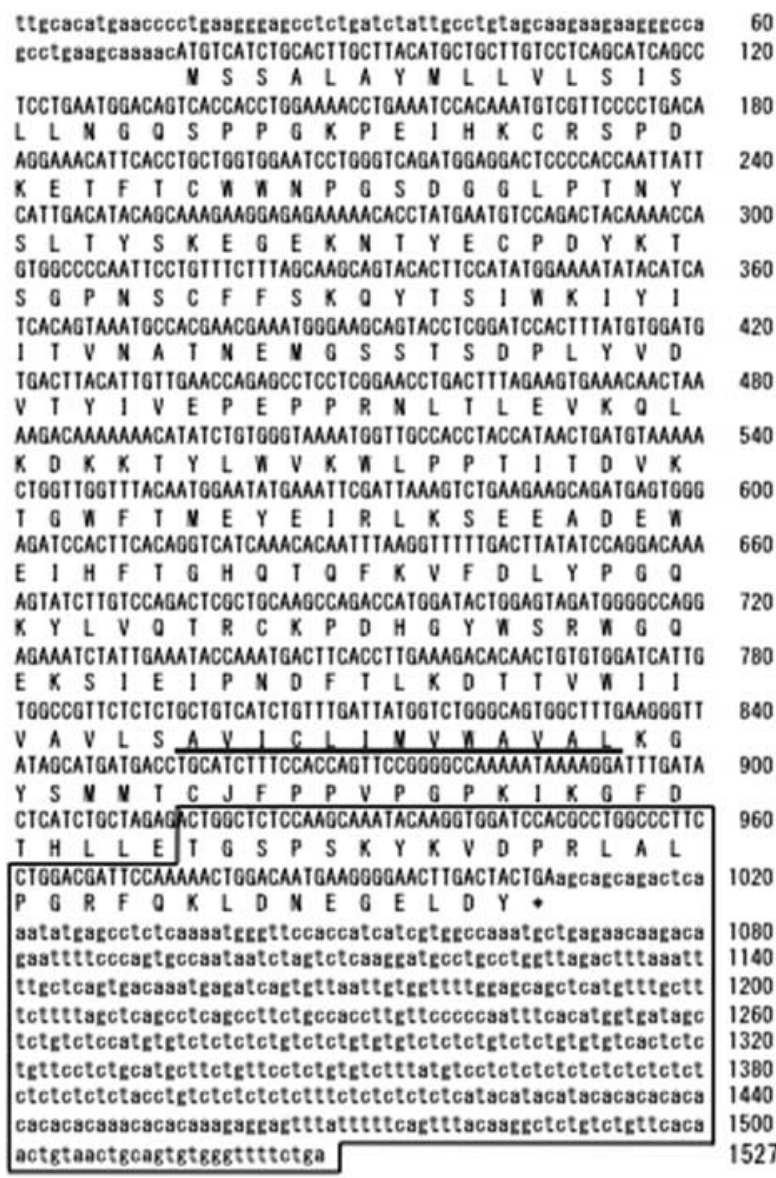

(B)

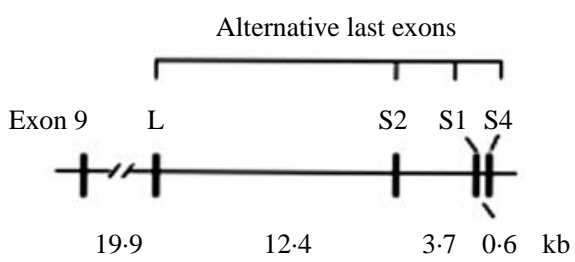

Figure 5 Nucleotide sequence of Prlr-S4 cDNA that encodes short-form PRLR. (A) The deduced amino acid sequence is shown under the cDNA sequence. The transmembrane domain is denoted with a thick underline. The unique region encoded by an alternative last exon is boxed. (B) The diagrams show arrangement of the four last exons. The exons in the gene are represented by vertical bars.

in terms of both their sequence and positional arrangement in Prlr gene (Hu et al. 1996, Kobayashi et al. 2007). The tissue expression patterns of each of the first exon variants of murine Prlr mRNA were also comparable to those of the rat counterparts, except for the silent expression of $m E 1_{1}$-Prlr mRNA in all the tissues analyzed. In rats, $\mathrm{E} 1_{1}$ has been shown to be a gonad-specific first exon activated by steroidogenic factor 1 (SF-1 (NR5A1); Hu et al. 1997). Although, $m E 1_{1}$-Prlr mRNA has been detected in a murine Leydig tumor cell line, the expression level was very low due to the absence of the functional SF-1 binding element in the promoter region ( $\mathrm{Hu}$ et al. 1997, 1998). In our present study, mE1 ${ }_{3}$-PRLR was the only Prlr mRNA detected in the ovary, suggesting that the Prlr gene expression in the mouse ovary depends on the transcription of $\mathrm{mE}_{3}$.

In the murine choroid plexus, $m E 1_{5}, m E 1_{4}$, and $m E 1_{5}$ PrlrmRNAs were expressed in a similar manner as in the rat choroid plexus. It has been previously demonstrated that the expression level of Prlr mRNA in the rat choroid plexus increases to the highest level during lactation (Augustine et al. 2003, Anderson et al. 2008) and is accompanied by a high serum PRL level (Escalada $e t$ al. 1996, Augustine et al. 2003). These findings suggest that Prlrgene expression in the choroid plexus is upregulated by PRL. Our present study showed that the expression levels of $m E 1_{5}, m E 1_{4}$, and $m E 1_{5}-P r l r$ mRNAs in the murine choroid plexus were more increased in the lactating mice than in the diestrus mice, with a particularly large increase in the levels of $m E 1_{4} P r l r$ mRNA. Furthermore, the expression level of $m E 1_{4} \mathrm{Prlr}$ mRNA but not $m E 1_{5}$ or $m E 1_{5}-$ PrlrmRNAs were decreased in the $\mathrm{Prl}^{-/-}$mice compared with the corresponding levels in the $\mathrm{Prl}^{+/-}$mice. These results indicate that PRL upregulates the expression of $m E 1_{4} P r l r$ mRNA in the murine choroid plexus and that the increased expression of $m E 1_{3}$ and $m E 1_{5}-\mathrm{Prlr}$ mRNAs at lactation may depend on factors other than PRL. It has been previously shown that estrogen upregulates Prlr gene expression in the choroid plexus ( $\mathrm{Pi}$ et al. 2003) as well as $\mathrm{Prl}$ gene expression in the pituitary gland (Shull \& Gorski 1990, Kansra et al. 2005). Our experiments in this study
(A)

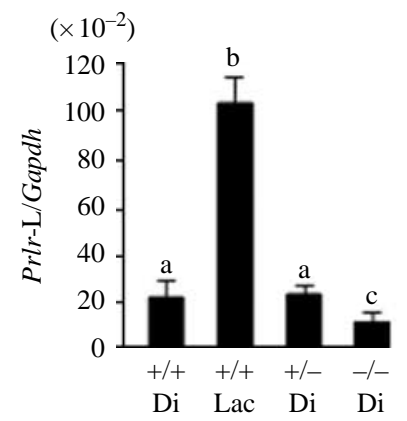

(B)

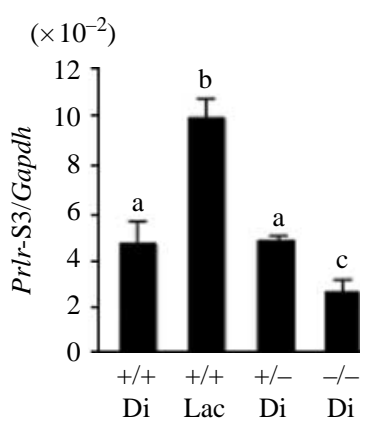

Figure 6 Expression levels of the last exon variants of PrIrmRNA in the choroid plexus of diestrus, lactating, and PRL-deficient mice. The expression levels of (A) Prlr-L and (B) Prlr-S4 mRNAs in diestrus (Di), day 3 lactating (Lac) $\mathrm{Prl}^{+/+}, \mathrm{Prl}^{+/-}$, and $\mathrm{Prl}^{-1-}$ mice were determined by real-time PCR. Values are expressed as relative to the value of Gapdh mRNA, and they represent mean \pm S.D. $(n=4)$. Values with different letters are significantly different $(P<0.05)$. 
involving the ovariectomized mice showed that estrogen upregulates the expression of $m E 1_{4} P r l r$ mRNAs in the $\mathrm{Prl}^{+}{ }^{-}$mice but not in the $\mathrm{Prl}^{-/-}$mice. These findings indicate that the upregulating effect of estrogen on the expression of murine Prlr gene is mediated through the transcriptional activation of $\mathrm{mE}_{4}$ by PRL, whose production is stimulated by estrogen.

The expression of the long- and short-form Prlr mRNAs has been observed previously in the rat choroid plexus. Similarly, PRLR-L, the long-form variant, and PRLR-S4, the murine ortholog of the rat short-form PRLR, were expressed in the mouse choroid plexus. Prlr-S3 cDNA cloned from the liver of a Swiss Webster strain showed high sequence similarity with the rat short-form PRLR, but it encoded a truncated form of PRLR consisting of 97 amino acids and, therefore, is considered as a product of a pseudogene (Davis \& Linzer 1989). However, the sequence of Prlr-S4 cDNA was completely identical with that of the corresponding regions of Prlr gene of the C57BL/6 strain, and no pseudogene sequence was found in this mouse strain. In the rat choroid plexus, the expression levels of both the mRNAs increase during lactation (Ouhtit et al. 1993, Bakowska \& Morrell 1997, Augustine et al. 2003, Nogami et al. 2007). In this study, the expression levels of the PRLR-L and PRLR-S4 variants were significantly increased in the lactating mice compared with those in the diestrus mice and were decreased in the PRL-deficient mice compared with the levels in the PRL-normal (i.e. $\mathrm{Prl}^{+/+}$and $\mathrm{Prl}^{+/-}$) mice. These expression patterns are similar to those of $m E 1_{4} P r l r$ mRNA, indicating that the expression of $\operatorname{Prl} r L$ and Prlv-S4 mRNAs in the choroid plexus largely depend on the transcriptional activation of $\mathrm{mE} 1_{4}$ first exon by PRL.

It is well known that the JAK2/STAT5 pathway is a major intracellular signaling pathway of the long-form PRLR. In this pathway, binding of PRL to the long-form receptor activates the kinase JAK2 and subsequently the transcription factor STAT5 by phosphorylation. In the murine choroid plexus, the amount of phosphorylated STAT5 is increased by the administration of PRL (Brown et al. 2010). Collectively, these findings suggest that the JAK2/STAT5 pathway is activated by PRL action on the long-form PRLR, and the activated STAT5 stimulates the Prlr gene expression by transcriptional activation of $\mathrm{mE}_{4}$ in the murine choroid plexus. In addition, they also suggest that the increased long and/or short forms of PRLR facilitate the uptake of blood PRL into the CSF by the receptor-mediated transport system. However, the molecular mechanisms of transcriptional activation of $\mathrm{mE} 1_{4}$ first exon and the PRLR-mediated transport system of PRL in the choroid plexus remain to be elucidated.

In conclusion, our present study demonstrated the presence of $\mathrm{mE} 1_{4}$, and $\mathrm{mE} 1_{5}$ first exons in addition to the known $\mathrm{mE} 1_{1}, \mathrm{mE}_{1}$, and $\mathrm{mE} 1_{3}$ first exons in murine
Prlr gene. Our experiments also revealed the tissue expression pattern of each first exon variant of Prlr mRNA. The expression level of $m E 1_{4} P r l r$ mRNA in the choroid plexus was markedly increased in the lactating mice and was significantly decreased in the PRLdeficient mice. PRL administration, but not estrogen, to the ovariectomized PRL-deficient mice significantly recovered the expression level of $m E 1_{4} P r l r$ mRNA. The expression levels of long- and short-form Prlr mRNAs were closely related to those of $m E 1_{4} P r l r$. These data suggest that PRL upregulates transcription of $\mathrm{mE} 1_{4}$ first exon mainly through the long-form PRLR signaling pathway in the murine choroid plexus.

\section{Declaration of interest}

The authors declare that there is no conflict of interest that could be perceived as prejudicing the impartiality of the research reported.

\section{Funding}

This work was supported in part by the Japan Pet Care Association.

\section{References}

Anderson GM, Kieser DC, Steyn FJ \& Grattan DR 2008 Hypothalamic prolactin receptor messenger ribonucleic acid levels, prolactin signaling, and hyperprolactinemic inhibition of pulsatile luteinizing hormone secretion are dependent on estradiol. Endocrinology 149 1562-1570. (doi:10.1210/en.2007-0867)

Augustine RA, Kokay IC, Andrews ZB, Ladyman SR \& Grattan DR 2003 Quantitation of prolactin receptor mRNA in the maternal rat brain during pregnancy and lactation. Journal of Molecular Endocrinology 31 221-232. (doi:10.1677/jme.0.0310221)

Bakowska JC \& Morrell JI 1997 Atlas of the neurons that express mRNA for the long form of the prolactin receptor in the forebrain of the female rat. Journal of Comparative Neurology 386 161-177. (doi:10.1002) (SICI) 1096-9861 (19970922)386:2<161::AID-CNE1 > 3.0.CO;2-)

Bole-Feysot C, Goffin V, Edery M, Binart N \& Kelly PA 1998 Prolactin (PRL) and its receptor: actions, signal transduction pathways and phenotypes observed in PRL receptor knockout mice. Endocrine Reviews 19 225-268. (doi:10.1210/er.19.3.225)

Boutin JM, Edery M, Shirota M, Jolicoeur C, Lesueur L, Ali S, Gould D, Djiane J \& Kelly PA 1989 Identification of a cDNA encoding a long form of prolactin receptor in human hepatoma and breast cancer cells. Molecular Endocrinology 3 1455-1461. (doi:10.1210/mend-3-9-1455)

Brown RS, Kokay IC, Herbison AE \& Grattan DR 2010 Distribution of prolactin-responsive neurons in the mouse forebrain. Journal of Comparative Neurology 518 92-102. (doi:10.1002/cne.22208)

Brooks PJ, Funabashi T, Kleopoulos SP, Mobbs CV \& Pfaff DW 1992 Prolactin receptor messenger RNA is synthesized by the epithelial cells of the choroid plexus. Brain Research. Molecular Brain Research 16 163-167. (doi:10.1016/0169-328X(92)90207-R)

Chiu S \& Wise PM 1994 Prolactin receptor mRNA localization in the hypothalamus by in situ hybridization. Journal of Neuroendocrinology 6 191-199. (doi:10.1111/j.1365-2826.1994.tb00572.x)

Chiu S, Koos RD \& Wise PM 1992 Detection of prolactin receptor (PRL-R) mRNA in the rat hypothalamus and pituitary gland. Endocrinology 130 1747-1749. (doi:10.1210/en.130.3.1747)

Clarke DL \& Linzer DI 1993 Changes in prolactin receptor expression during pregnancy in the mouse ovary. Endocrinology 133 224-232. (doi:10.1210/en.133.1.224) 
Das R \& Vonderhaar BK 1995 Transduction of prolactin's (PRL) growth signal through both long and short forms of the PRL receptor. Molecular Endocrinology 9 1750-1759. (doi:10.1210/me.9. 12.1750)

Davis JA \& Linzer DI 1989 Expression of multiple forms of the prolactin receptor in mouse liver. Molecular Endocrinology 3 674-680. (doi:10.1210/mend-3-4-674)

Di Carlo R, Muccioli G, Papotti M \& Bussolati G 1992 Characterization of prolactin receptor in human brain and choroid plexus. Brain Research 570 341-346. (doi:10.1016/0006-8993(92)90599-5)

Escalada J, Cacicedo L, Ortego J, Melian E \& Sánchez-Franco F 1996 Prolactin gene expression and secretion during pregnancy and lactation in the rat: role of dopamine and vasoactive intestinal peptide. Endocrinology 137 631-637. (doi:10.1210/en.137.2.631)

Freeman ME, Kanyicska B, Lerant A \& Nagy G 2000 Prolactin: structure, function, and regulation of secretion. Physiological Reviews 80 1523-1631.

Fujikawa T, Soya H, Yoshizato H, Sakaguchi K, Doh-Ura K, Tanaka M \& Nakashima K 1995 Restraint stress enhances the gene expression of prolactin receptor long form at the choroid plexus. Endocrinology 136 5608-5613. (doi:10.1210/en.136.12.5608)

Fujikawa T, Soya H, Tamashiro KL, Sakai RR, McEwen BS, Nakai N, Ogata M, Suzuki I \& Nakashima K 2004 Prolactin prevents acute stress-induced hypocalcemia and ulcerogenesis by acting in the brain of rat. Endocrinology 145 2006-2013. (doi:10.1210/en.20031446)

Horseman ND, Zhao W, Montecino-Rodriguez E, Tanaka M, Nakashima K, Engle SJ, Smith F, Markoff E \& Dorshkind K 1997 Defective mammopoiesis, but normal hematopoiesis, in mice with a targeted disruption of the prolactin gene. EMBO Journal 16 6926-6935. (doi:10.1093/emboj/16.23.6926)

Hu Z, Zhuang L \& Dufau ML 1996 Multiple and tissue-specific promoter control of gonadal and non-gonadal prolactin receptor gene expression. Journal of Biological Chemistry 271 110242-110246. (doi:10.1074/jbc.271.17.10242)

Hu Z, Zhuang L, Guan X, Meng J \& Dufau M 1997 Steroidgenic factor-1 is an essential transcriptional activator for gonad-specific expression of promoter I of the rat prolactin receptor gene. Journal of Biological Chemistry 272 14263-14271. (doi:10.1074/jbc. 272.22.14263)

Hu Z, Zhuang L, Meng J \& Dufau ML 1998 Transcriptional regulation of the generic promoter III of the rat prolactin receptor gene by C/EBP $\beta$ and SP1. Journal of Biological Chemistry 273 26225-26235. (doi:10.1074/jbc.273.40.26225)

Hu Z, Zhuang L, Meng J, Leondires M \& Dufau ML 1999 The human prolactin receptor gene structure and alternative promoter utilization: the generic promoter hPIII and a novel human promoter hP(N). Journal of Clinical Endocrinology and Metabolism 84 1153-1156. (doi:10.1210/jc.84.3.1153)

Hu ZZ, Zhuang L, Meng J, Tsai-Morris CH \& Dufau ML 2002 Complex $5^{\prime}$ genomic structure of the human prolactin receptor: multiple alternative exons 1 and promoter utilization. Endocrinology 143 2139-2142. (doi:10.1210/en.143.6.2139)

Kansra S, Yamagata S, Sneade L, Foster L \& Ben-Jonathan N 2005 Differential effects of estrogen receptor antagonists on pituitary lactotroph proliferation and prolactin release. Molecular and Cellular Endocrinology 239 27-36. (doi:10.1016/j.mce.2005.04.008)

Kobayashi M, Suzuki M, Saito TR \& Tanaka M 2007 Developmental changes in the expression levels of alternative first exons of prolactin receptor gene in rat brain. Endocrine Research 32 143-151. (doi:10.1080/07435800701764022)

Mangurian LP, Walsh RJ \& Posner BI 1992 Prolactin enhancement of its own uptake at the choroid plexus. Endocrinology 131 698-702. (doi:10.1210/en.131.2.698)

Maruyama K \& Sugano S 1994 Oligo-capping: a simple method to replace the cap structure of eukaryotic mRNAs with oligoribonucleotides. Gene 138 171-174. (doi:10.1016/0378-1119(94)90802-8)
Moldrup A, Ormandy C, Nagano M, Murthy K, Banville D, Tronche F \& Kelly PA 1996 Differential promoter usage in prolactin receptor gene expression: hepatocyte nuclear factor 4 binds to and activates the promoter preferentially active in the liver. Molecular Endocrinology 10 661-671. (doi:10.1210/me.10.6.661)

Moore RC \& Oka T 1993 Cloning and sequencing of the cDNA encoding the murine mammary gland long-form prolactin receptor. Gene 134 263-265. (doi:10.1016/0378-1119(93)90104-B)

Muccioli G \& Di Carlo R 1994 Modulation of prolactin receptors in the rat hypothalamus in response to changes in serum concentration of endogenous prolactin or to ovine prolactin administration. Brain Research 663 244-250. (doi:10.1016/0006-8993(94)91269-6)

Nagano M \& Kelly PA 1994 Tissue distribution and regulation of rat prolactin receptor gene expression. Quantitative analysis by polymerase chain reaction. Journal of Biological Chemistry 269 13337-13345.

Nogami H, Hoshino R, Ogasawara K, Miyamoto S \& Hisano S 2007 Region-specific expression and hormonal regulation of the first exon variants of rat prolactin receptor mRNA in rat brain and anterior pituitary gland. Journal of Neuroendocrinology 19 583-593. (doi:10.1111/j.1365-2826.2007.01565.x)

Ouhtit A, Morel G \& Kelly PA 1993 Visualization of gene expression of short and long forms of prolactin receptor in the rat. Endocrinology 133 135-144. (doi:10.1210/en.133.1.135)

Pi XJ \& Grattan DR 1999 Increased expression of both short and long forms of prolactin receptor mRNA in hypothalamic nuclei of lactating rats. Journal of Molecular Endocrinology 23 13-22. (doi:10.1677/jme.0.0230013)

Pi X, Zhang B, Li J \& Voogt JL 2003 Promoter usage and estrogen regulation of prolactin receptor gene in the brain of the female rat. Neuroendocrinology 77 187-197. (doi:10.1159/000069510)

Shirota M, Banville D, Ali S, Jolicoeur C, Boutin JM, Edery M, Djiane J \& Kelly PA 1990 Expression of two forms of prolactin receptor in rat ovary and liver. Molecular Endocrinology 4 1136-1143. (doi:10.1210/ mend-4-8-1136)

Shull JD \& Gorski J 1990 Regulation of prolactin gene transcription in vivo: interactions between estrogen, pimozide, and alphaergocryptine. Molecular Pharmacology 37 215-221.

Sugiyama T, Minoura H, Toyoda N, Sakaguchi K, Tanaka M, Sudo S \& Nakashima K 1996 Pup contact induces the expression of long form prolactin receptor mRNA in the brain of female rats: effects of ovariectomy and hypophysectomy on receptor gene expression. Journal of Endocrinology 149 335-340. (doi:10.1677/joe.0.1490335)

Tanaka M, Hayashida Y, Iguchi T, Nakao N, Suzuki M, Nakai N \& Nakashima K 2002 Identification of a novel first exon of prolactin receptor gene expressed in the rat brain. Endocrinology 143 2080-2084. (doi:10.1210/en.143.6.2080)

Tanaka M, Suzuki M, Kawana T, Segawa M, Yoshikawa M, Mori M, Kobayashi M, Nakai N \& Saito TR 2005 Differential effects of sex steroid hormones on the expressions of multiple first exons including a novel first exon of prolactin receptor gene in the rat liver. Journal of Molecular Endocrinology 34 667-673. (doi:10.1677) jme.1.01702)

Trott JF, Hovey RC, Koduri S \& Vonderhaar BK 2003 Alternative splicing to exon 11 of human prolactin receptor gene results in multiple isoforms including a secreted prolactin-binding protein. Journal of Molecular Endocrinology 30 31-47. (doi:10.1677/jme.0. 0300031)

Walsh RJ, Slaby FJ \& Posner BI 1987 A receptor-mediated mechanism for the transport of prolactin from blood to cerebrospinal fluid. Endocrinology 120 1846-1850. (doi:10.1210/endo-120-5-1846)

Received in final form 5 January 2012

Accepted 31 January 2012

Made available online as an Accepted Preprint 31 January 2012 